Cahiers $d u$ MONDE RUSSE

\section{Cahiers du monde russe}

Russie - Empire russe - Union soviétique et États indépendants

$47 / 4 \mid 2006$

Varia

\title{
Vincent Burnett, The Russian Revolutionary \\ Economy, 1890-1940
}

\section{Alessandro Stanziani}

\section{OpenEdition}

\section{Journals}

Édition électronique

URL : https://journals.openedition.org/monderusse/6714

DOI : 10.4000/monderusse.6714

ISSN : $1777-5388$

Éditeur

Éditions de l'EHESS

\section{Édition imprimée}

Date de publication : 30 décembre 2006

Pagination : 824-825

ISBN : 978-2-7132-2098-2

ISSN : $1252-6576$

Référence électronique

Alessandro Stanziani, «Vincent Burnett, The Russian Revolutionary Economy, 1890-1940 », Cahiers du monde russe [En ligne], 47/4 | 2006, mis en ligne le 03 juillet 2009, consulté le 03 septembre 2022 URL : http://journals.openedition.org/monderusse/6714; DOI : https://doi.org/10.4000/monderusse. 6714

Ce document a été généré automatiquement le 3 septembre 2022.

Tous droits réservés 


\title{
Vincent Burnett, The Russian Revolutionary Economy, 1890-1940
}

\author{
Alessandro Stanziani
}

\section{RÉFÉRENCE}

Vincent BURNETT, The Russian Revolutionary Economy, 1890-1940. Londres-New York : Routledge, 2004, 144 p.

1 Ce court ouvrage est un manuel destiné aux étudiants de maîtrise et de doctorat. Dans cette perspective, il est sans doute méritoire que Vincent Burnett s'efforce de relier l'histoire économique "factuelle» de la Russie et de l'URSS à celle de la pensée économique. Ce lien n'avait jusqu'à présent été développé que dans quelques ouvrages destinés aux spécialistes. Autre aspect novateur, tant par rapport à la majorité des manuels existants que des approches des économistes, l'auteur met en relief dans son étude l'analyse des solutions alternatives disponibles à chaque époque. La prise en compte des bifurcations historiques permet de sortir d'une approche déterministe, partagée aussi bien par certains historiens que par les économistes. Burnett développe ces arguments en se fondant sur les théories économiques récentes, dites néo-institutionnalistes, qui cherchent à dépasser l'opposition entre économie libérale et économie socialiste en montrant que les institutions, y compris celles du marché, répondent à des logiques économiques et pas seulement politiques. Inversement, les marchés s'appuient toujours sur des normes et des institutions.

2 Encore faut-il comprendre comment cette approche permet de rendre compte de l'évolution de l'économie russe et soviétique. Après un premier chapitre évoquant les principaux problèmes traités et la méthode employée, l'ouvrage étudie l'économie tsariste entre 1890 et 1913, puis l'économie "révolutionnaire » (1914-1921) et «bolchevique» (1921-1929), et enfin l'économie «stalinienne» (1929-1940). La conclusion fait le point sur l'évolution actuelle de la Russie. 
L'auteur insiste sur la croissance importante, quoique peu équilibrée, de l'Empire tsariste, l'impact négatif de la guerre et le rôle du communisme de guerre, interprété comme un choix imposé par les événements. Il évoque également la sophistication de la pensée économique sous la NEP et la complexité de cette période. Enfin, l'étude de l'économie stalinienne amène l'auteur à avancer que l'opposition entre URSS et USA se situait moins entre « plan » et " marché réel » (la régulation intervenant aussi dans l'Amérique de Keynes et Roosevelt), qu'à un niveau idéologique. Car, des deux côtés, on s'efforçait de radicaliser les différences en exagérant la portée du marché (aux USA) ou du plan (en URSS). À partir de ce constat, l'auteur parvient à la conclusion que l'opposition entre marché et socialisme - ainsi que l'association entre économie soviétique et socialisme - méritent d'être repensées, ce qui ouvre la possibilité de concevoir, de nos jours, une véritable économie « socialiste».

Cette thèse, qui va à contre-courant des orientations idéologiques actuellement dominantes, serait sans doute plus convaincante, voire même intéressante, si elle ne s'appuyait pas sur des analyses en bonne partie biaisées de l'histoire économique russe et soviétique. Par exemple l'économie tsariste, à propos de laquelle l'auteur évoque encore la présence de structures «féodales» (terme désormais considéré comme largement inapproprié), ignore la composante impériale, pourtant centrale, de cette économie. De même, pour l'époque socialiste, les famines de 1921 et 1932-1933 sont totalement ignorées. Inversement, le poids politique des débats des économistes paraît quelque peu surévalué, surtout si l'on tient compte du rôle central du Politbjuro par rapport au Gosplan, et ce depuis les années 1920.

Le fait est que, même pour un manuel, la courte bibliographie finale apparaît extrêmement obsolète: certes, les titres de Gershenkron, Carr, Davies ou Gatrell y figurent, mais tant les analyses récentes sur l'économie tsariste et soviétique que des classiques comme les travaux de Moshe Lewin sur les «alternatives» des années 1920 font défaut.

Bref, cet ouvrage impose, plus que jamais, la nécessité de réexaminer l'histoire économique et celle des idées économiques, russes et soviétiques, sur la très longue durée en essayant de sortir des anciens débats idéologiques. Ce n'est qu'en tenant compte des progrès importants de l'historiographie, mais aussi de l'évolution des approches plus générales dans ce domaine, que l'on y parviendra. 